\section{Zum 150-jährigen Jubiläum des Palmenhauses}

Zum Jubiläum sollen ein paar alte Fotodokumente aus dem Jahr 1965 an den Bau der Galerien am Palmenhaus erinnern. Die Fotos stammen aus einem Fotoalbum, das die Bauarbeiten bis zur Eröffnung der Galerien im September 1965 dokumentiert. Das Album wurde von der beauftragten Firma Christian Henssler KG erstellt, das Album befindet sich im Archiv des Palmengartens.

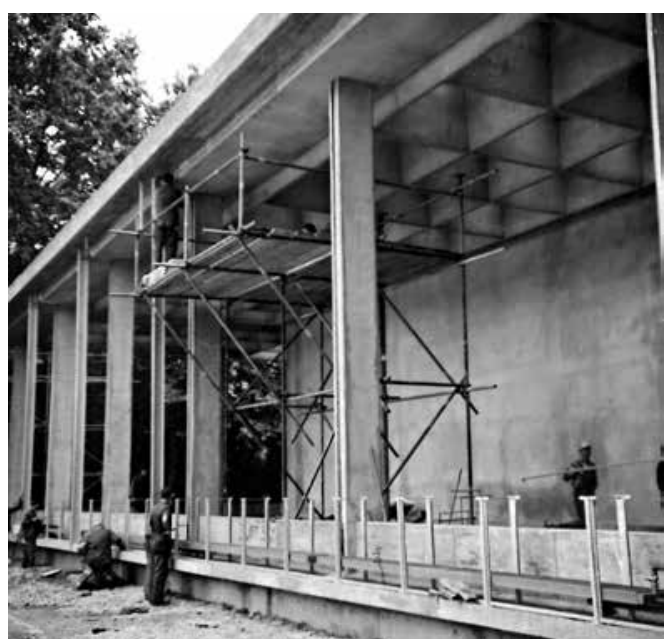

Abb. 2: Montage der Stahlstabilisatoren und der Konvektorenverkleidung.

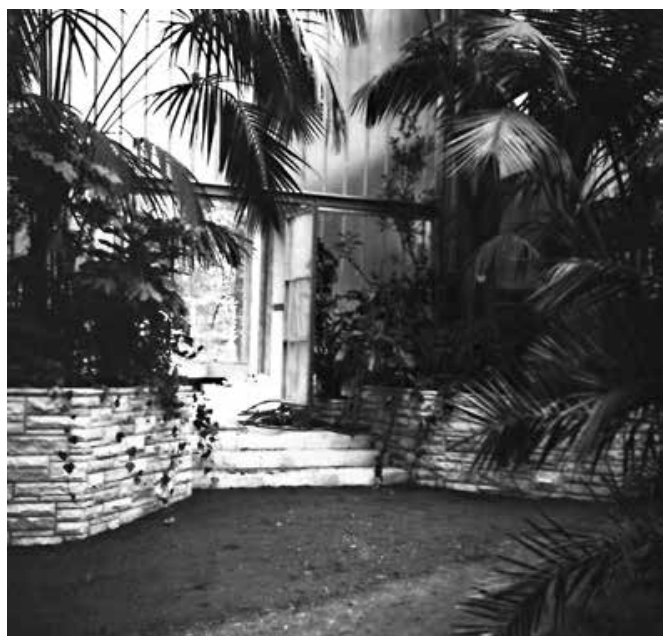

Abb. 4: Natursteinmauern im Palmenhaus.

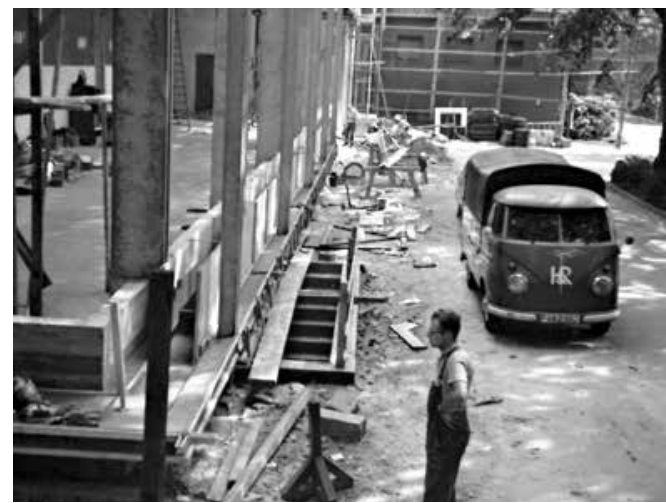

Abb. 1: Bauarbeiten auf der Galerie-Westseite.

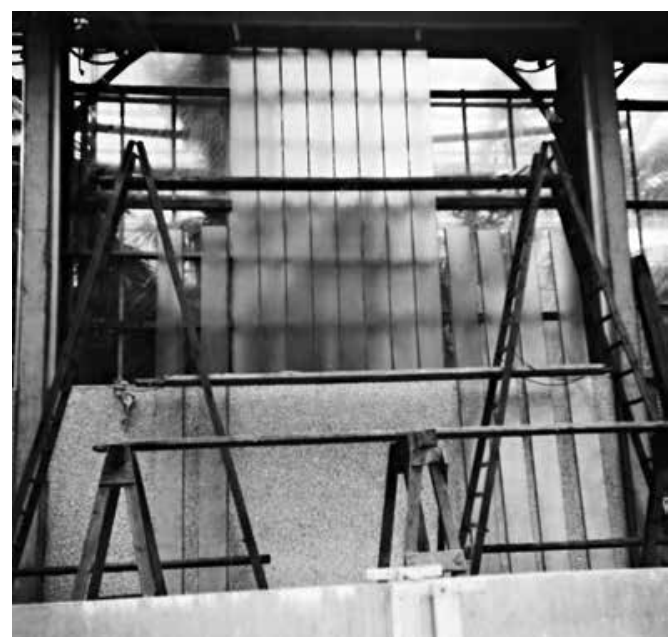

Abb. 3: Einbau der Profilit-Verglasung zum Palmenhaus hin.

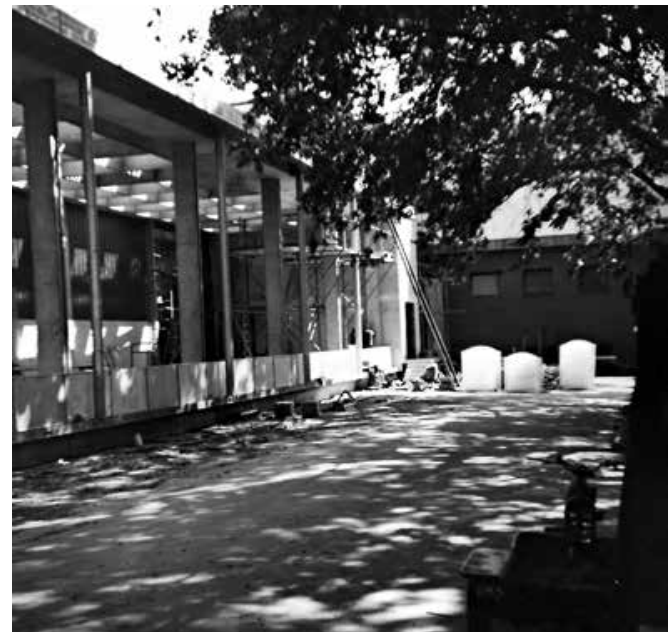

Abb. 5: Dachdeckerarbeiten und Einbau der Lichtkuppeln. 


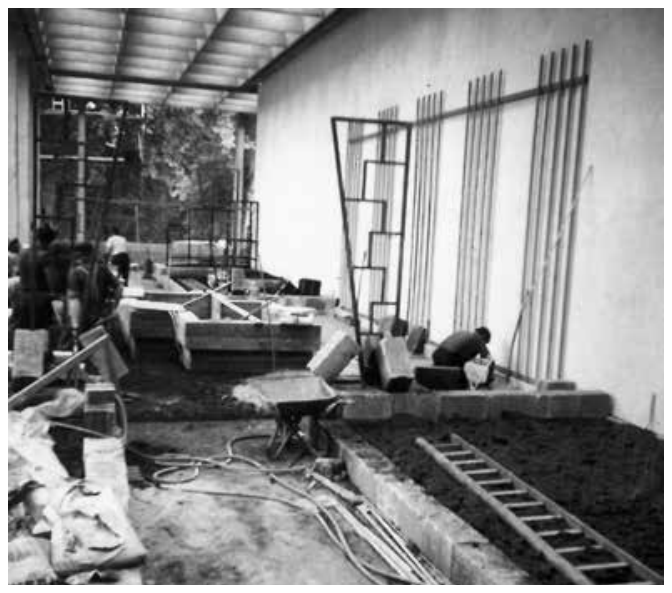

Abb. 6: Gestaltung des Wandbeetes.

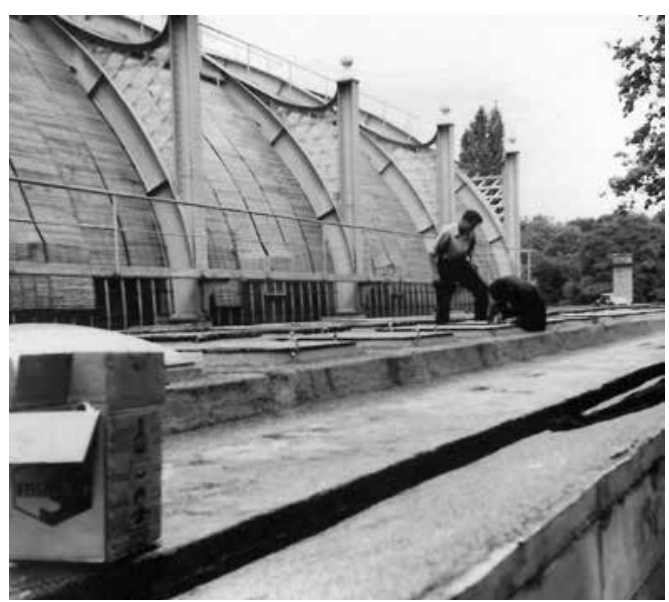

Abb. 8: Blick vom Galeriedach auf die Kuppel des Palmenhauses.

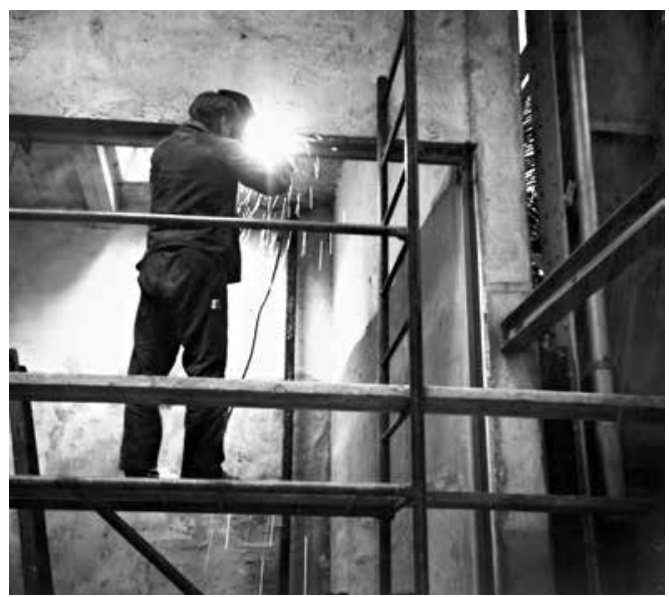

Abb. 10: Anstrich der Innenwand.

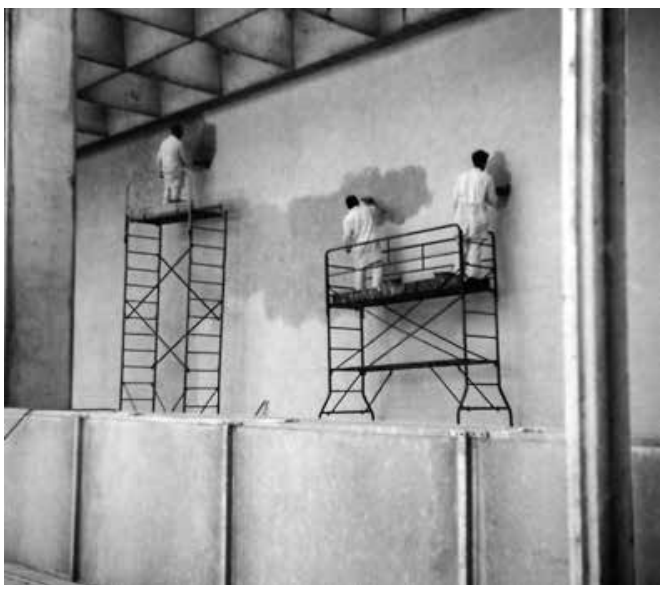

Abb. 7: Arbeiten im Lesesaal.

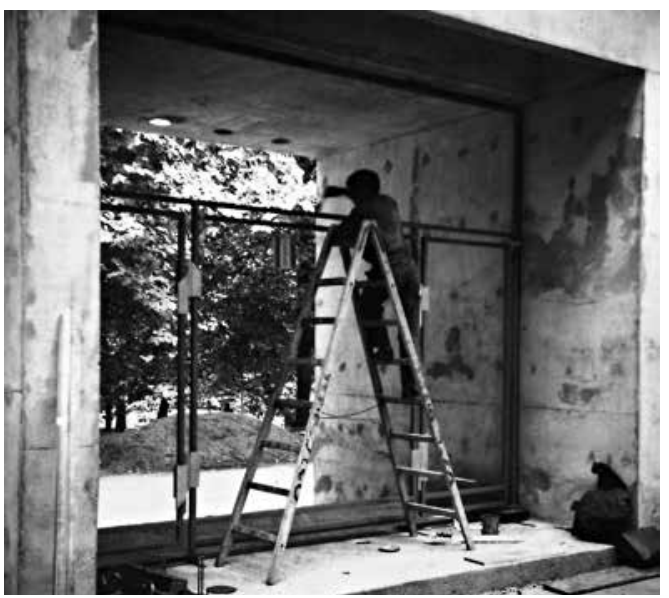

Abb. 9: Schlosserarbeiten an den Eingängen und für die Glaswand am Lesesaal (heute als Kleine Galerie bezeichnet).

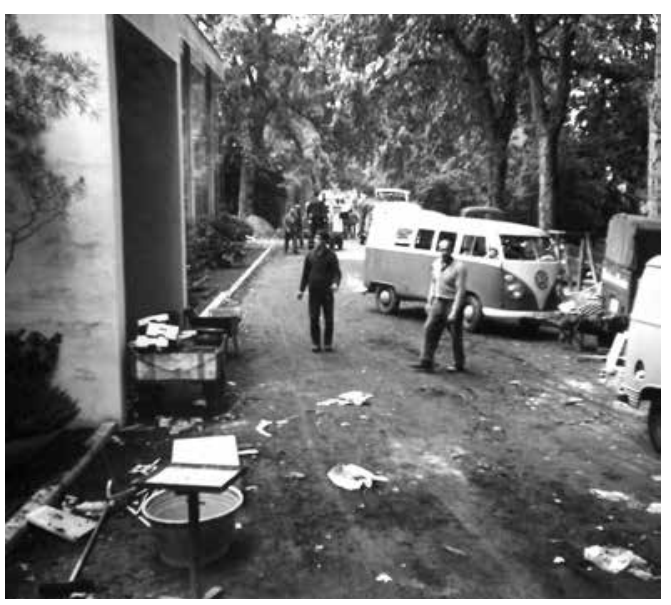

Abb. 11: Die Eröffnung steht bald bevor. 


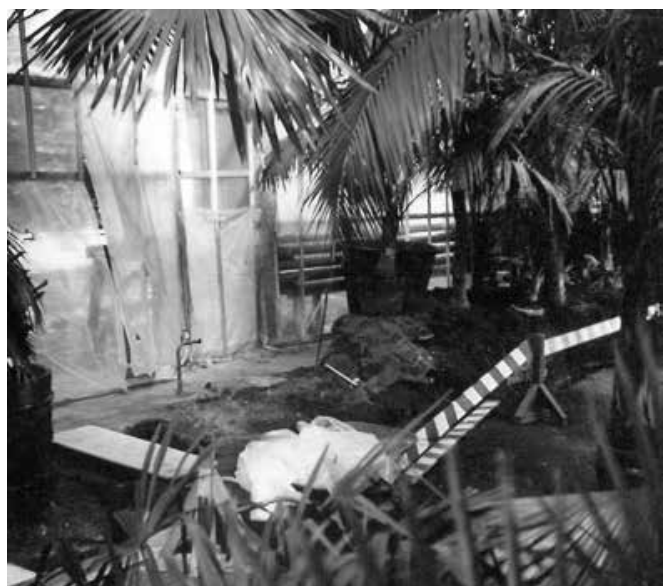

Abb. 12: Verbindung zum Palmenhaus.

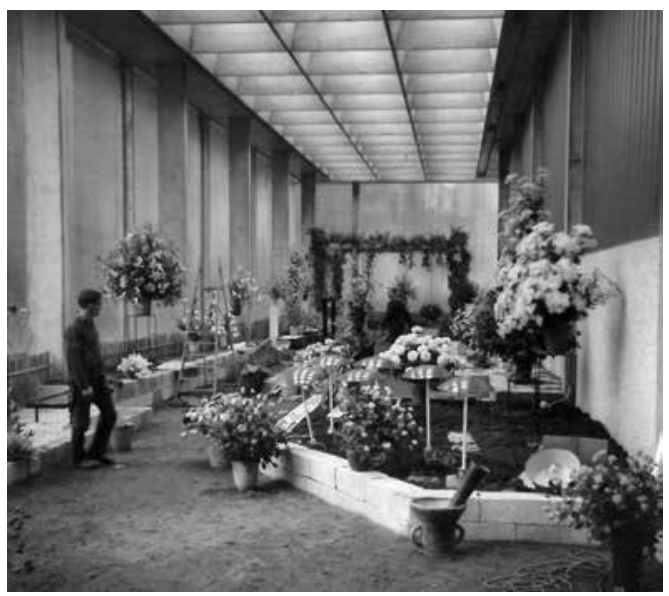

Abb. 14: 18 Stunden vor der Eröffnung

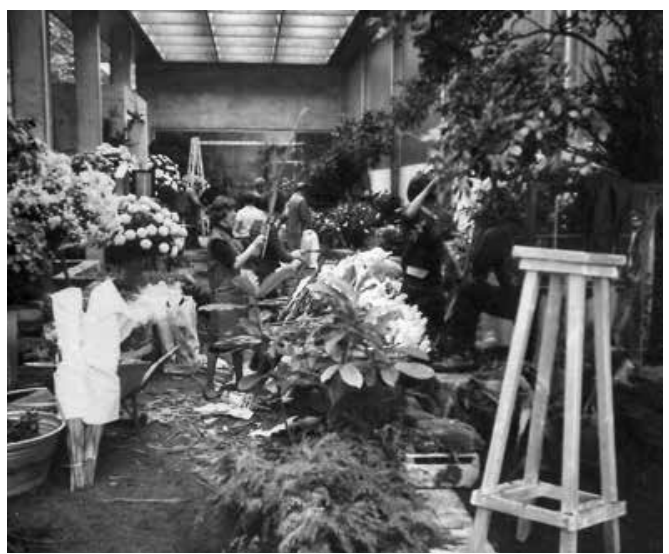

Abb. 16: Letzte Arbeiten kurz vor der Eröffnung.

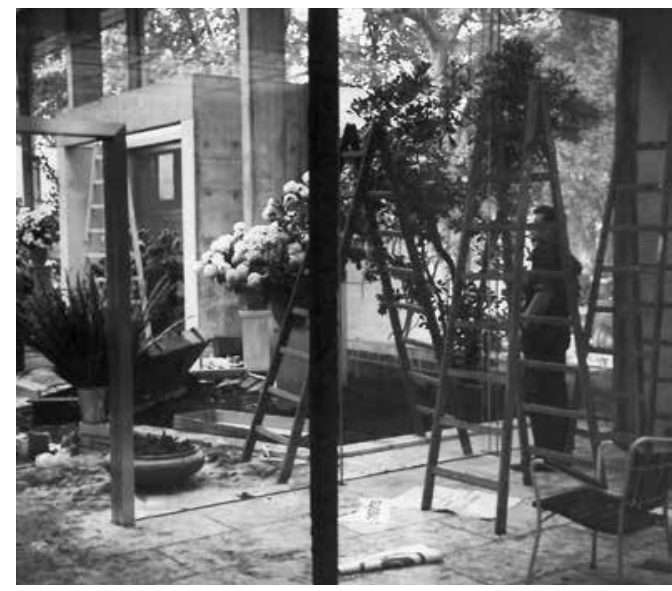

Abb. 13: Kurz vor der Eröffnung und Aufbau der ersten Ausstellung.

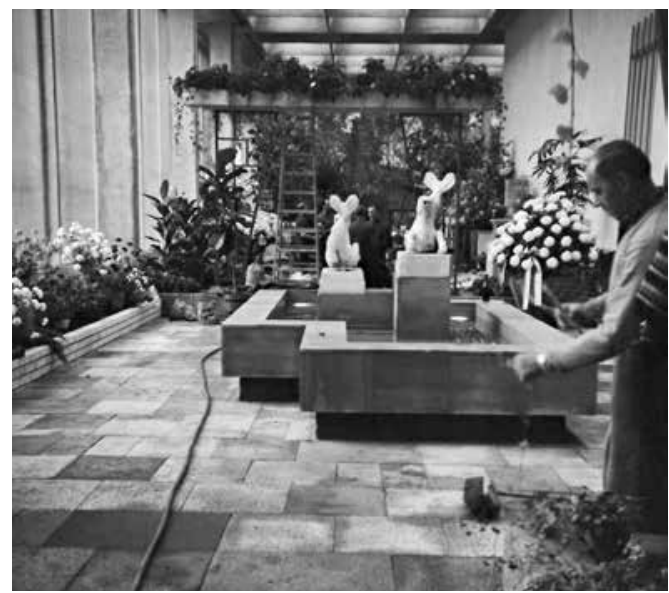

Abb. 15: Die Seepferdchen, die heute im Becken vor dem Direktionsgebäude stehen.

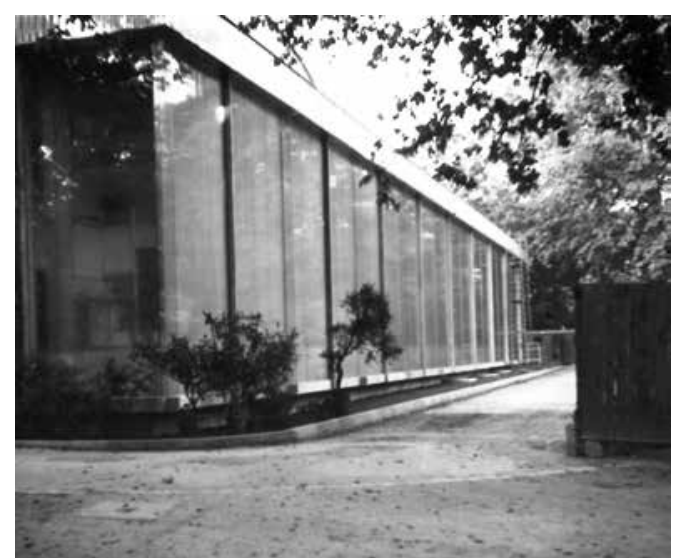

Abb. 17: Die Galerie von außen. 


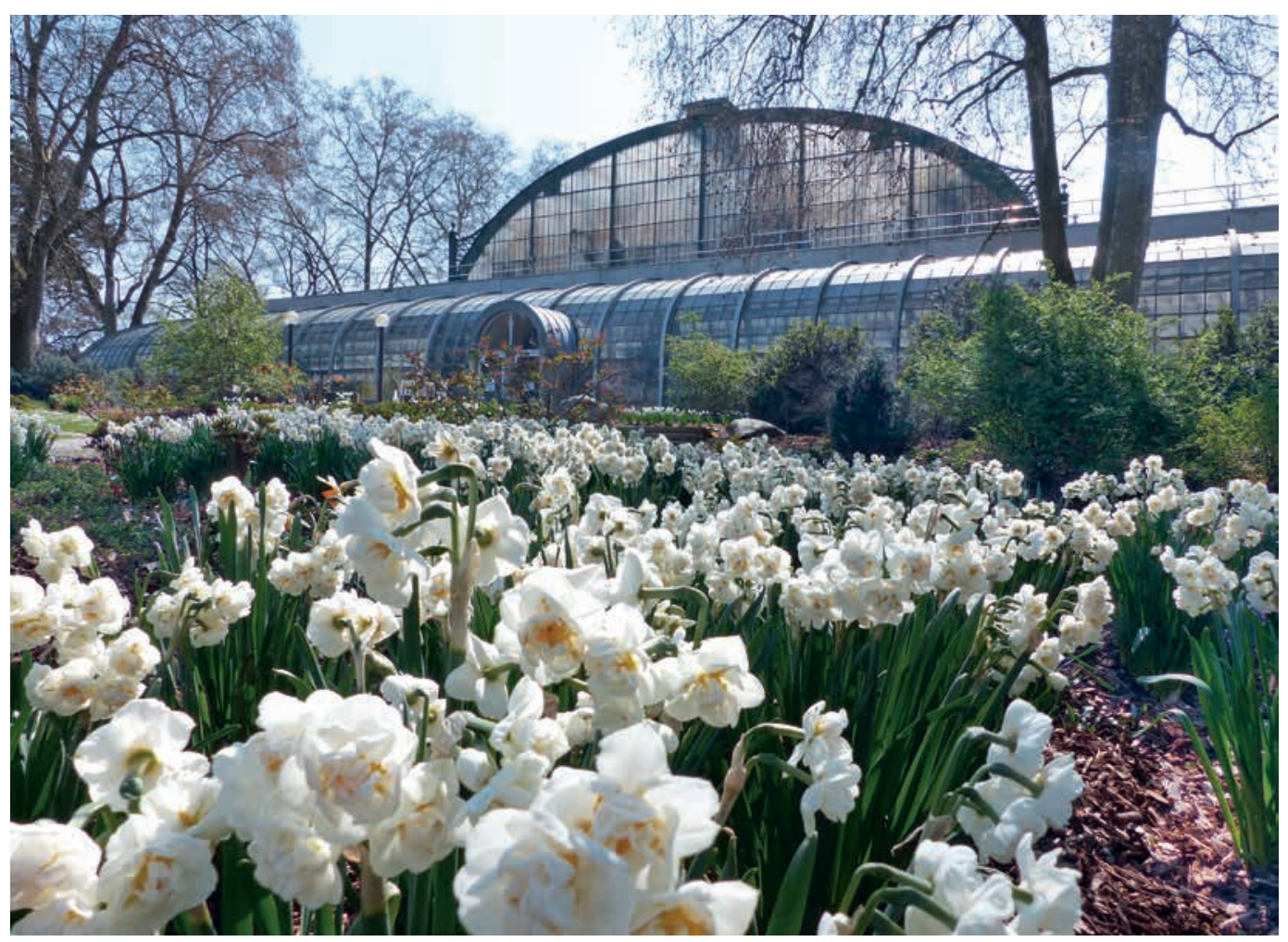

Abb. 18: Aktuelle Ansicht des Palmenhauses mit den beiden Galerien. (Foto: H. Steinecke)

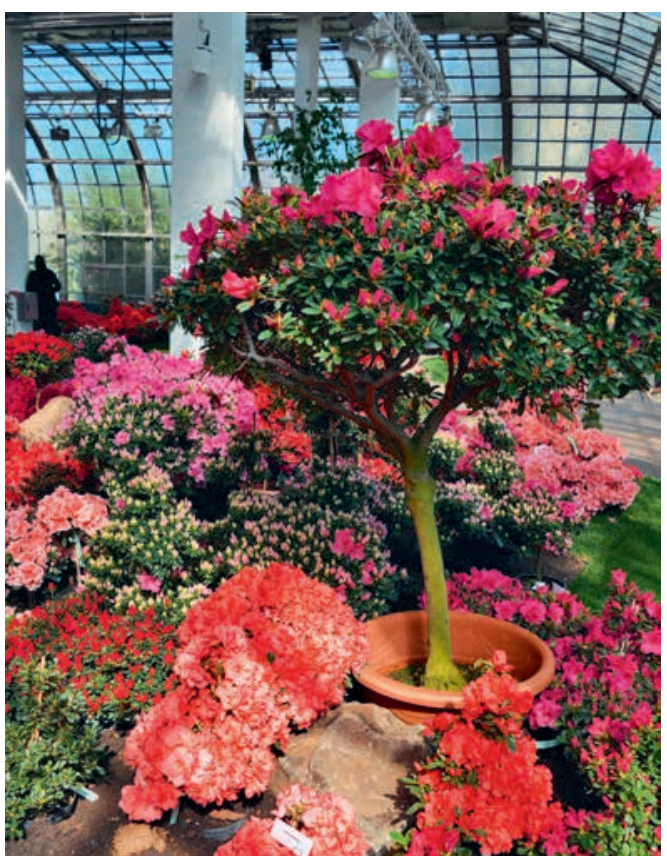

Abb. 19: Aktuelle Ansicht der Galerie West mit Azaleen-Ausstellung. (Foto: H. STEINECKe)

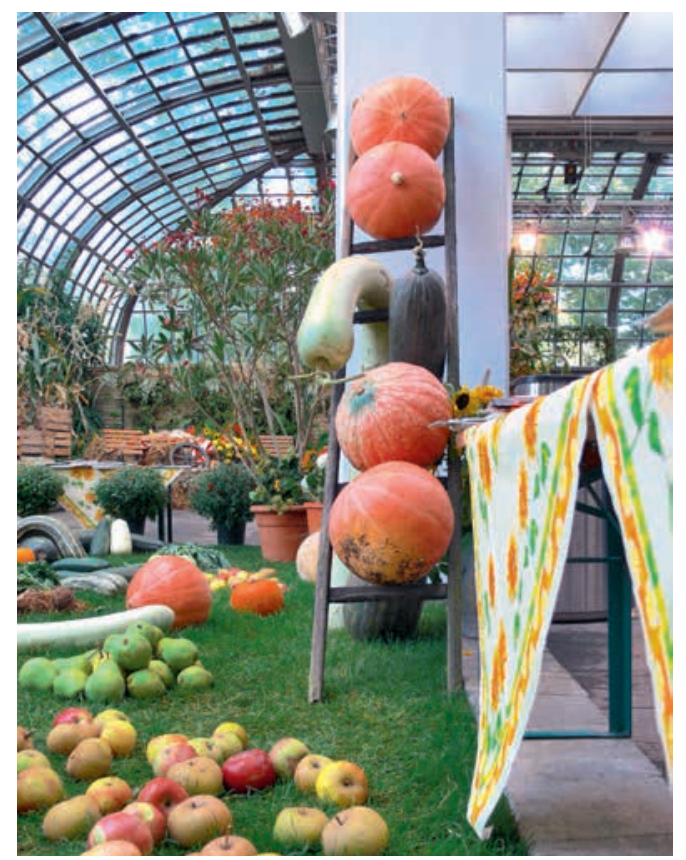

Abb. 20: Erntedank in der Galerie Ost.

(Foto: H. STEINECKe) 